\title{
ANÁLISIS PROXIMAL Y FISICOQUÍMICO DE PROPÓLEOS (PROPOLIS) PROVENIENTES DE APIARIOS BOYACENSES
}

\section{PROXIMAL AND PHYSICAL-CHEMISTRY ANALYSIS OF PROPOLIS FROM BY BOYACENSES APIARIES}

\section{Nataly Julieth Puerto Galindo 1; Gloria Astrid Prieto Suárez 2; Segundo Rafael Castro Guerrero ${ }^{3}$}

${ }^{1}$ Escuela de Posgrados de la Facultad de Ciencias-Programa Maestría en Química - Universidad Pedagógica y Tecnológica de Colombia (UPTC). Grupo de Investigación en Química y Tecnología de Alimentos, GIQTA.

${ }^{2}$ Grupo de Investigación en Química y Tecnología de Alimentos, GIQTA - Escuela de Ciencias Químicas - Facultad de Ciencias - Universidad Pedagógica y Tecnológica de Colombia (UPTC)

${ }^{3}$ Grupo de Investigación en Sistemas de Producción Sostenible, GIPSO - Facultad de Ciencias Agropecuarias, Escuela de Medicina Veterinaria y Zootecnia - Universidad Pedagógica y Tecnológica de Colombia (UPTC).

\section{Resumen}

El propóleo es una sustancia elaborada por Apis mellifera, de consistencia resinosa, compleja y aspecto variable, utilizado como cemento o producto sellante en la construcción de las colmenas brindando así mismo, protección contra distintos patógenos. Como alimento funcional, el propóleo evita la propagación de enfermedades al ofrecer innumerables propiedades terapéuticas demostradas ampliamente (antibacterianas, antiinflamatorias, anti-alergénicas y antitrombóticas). La caracterización proximal de los propóleos boyacenses provenientes de los apiarios de Boavita, San Mateo y Pesca permitió demostrar diferencias entre ellos. El propóleo más resinoso resultó ser el de Boavita $(38,03 \% \pm 0,04)$, seguido del propóleo de Pesca $(21,35 \% \pm 0,08)$ y San Mateo $(12,75 \% \pm 0,13)$. El mayor contenido de proteína lo estableció el propóleo proveniente de Pesca $(17,1 \% \pm$ 0,13), y los propóleos de Boavita y San Mateo presentaron contenidos menores, $10,1 \% \pm 0,03$ y $7,2 \% \pm 0,06$, respectivamente. La cantidad de fibra presentó un orden igual al contenido de proteína, con porcentajes del 11,5\% $\pm 0,35,10,1 \% \pm$ 0,03 y $7,9 \% \pm 0,03$, respectivamente. Los propóleos de estudio se concentran en conglomerados en forma de briquetas con variación del color desde amarillo claro hasta castaño oscuro. Tanto el método de recolección (raspado) y de 
127

almacenamiento como la riqueza de vegetación (plantas arbóreas, arbustivas y rastreras) de las provincias Norte y Sugamuxi de Boyacá, conceden características organolépticas, fisicoquímicas y bromatológicas únicas para cada propóleo.

Palabras Clave: Apiarios boyacenses, Caracterización fisicoquímica, Composición macroscópica, Propolis, Valor nutricional

\section{ABSTRACT}

Propolis is a substance produced by Apis mellifera, resinous consistency complex and variable appearance, used for the construction of hives as a cement or sealant product for protection against various pathogens. As functional food, propolis prevents the spread of disease by offering many therapeutic properties (antibacterial, anti-inflammatory, anti-allergenic and anti-thrombotic) amply demonstrated. The proximal characterization of boyacenses propolis from beehives of Boavita, San Mateo and Pesca to showed possible differences between them. The resinous propolis turned out to be that of Boavita $(38.03 \% \pm 0.04)$, followed by propóleo Pesca $(21.35 \% \pm 0.08)$ and San Mateo $(12.75 \% \pm 0.13)$. The protein content was higher in propolis from Pesca $(17.1 \% \pm 0.13)$ while propolis of San Mateo and Boavita had lower contents, $10.1 \% \pm 0.03$ y $7.2 \% \pm 0.06$, respectively. The amount of fiber showed same behavior that protein content, with percentages $11.5 \% \pm 0.35,10.1 \% \pm$ 0.03 and 7.9\% \pm 0.03 , for propolis Pesca, Boavita and San Mateo, respectively. All study propolis are concentrated in clusters in form of briquettes with color variation from light yellow to dark brown. Both the collection method (scraping) and storage as well as the richness of vegetation (arboreal plants, shrubs and creepers) of the North and Sugamuxi of Boyaca provinces, granted organoleptic, physicochemical and unique bromatological characteristics for each propolis.

Keywords: Boyacenses apiaries, Physicochemical characterization, Macroscopic composition, Propolis, Nutritional value.

*Para citar este artículo: Puerto Galindo NJ; Prieto Suárez GA ; Castro Guerrero SR. Anàlisis proximal y fisicoquímico de propóleos(propolis) provenientes de apiarios Boyacenses. Revista Bistua. 2016. 14(2):126-140

+ Autor para el envió de correspondencia y la solicitud de las separatas: Nataly Julieth Puerto Galindo. Grupo de Investigación en Química y Tecnología de Alimentos, GIQTA. Universidad Pedagógica y Tecnológica de Colombia (UPTC) Tunja, Boyacá, Colombia. E-mail: nataly.puerto@uptc.edu.co. 


\section{Introducción}

El propóleo deriva del griego Propolis (Pro: En defensa de; Polis: Ciudad) y comúnmente es conocido como goma de las abejas ${ }^{1}$. Es un producto apícola elaborado a partir de la actividad de pecoreo que consiste en recoger con las mandíbulas, partículas resinosas, secreciones aromáticas y florales de las yemas, brotes de arbustos y árboles (como pino (Pinus sylvestris), abeto (Gragntraeet ), roble (Quercus humboldtii), sauce (Salix babylónica), abedul (Betula pendula), álamo (Populus) y olmo (Ulmus minor)), para mezclarlas con secreciones salivares que en conjunto sintetizan el propóleo ${ }^{2}$. Las abejas depositan el propóleo en las colmenas cumpliendo así roles importantes en la estructuración: cerrar rendijas, mantener estable la temperatura interna, recubrir el cuerpo de animales muertos al interior $y$ protegerla contra la proliferación de microorganismos ${ }^{2,3}$. Adicionalmente, según sea el origen botánico y geográfico, el propóleo adquiere consistencia viscosa de diferentes tonalidades: castaño, marrón, pardo, rojizo, verde y en ocasiones negro.

La composición química del propóleo varía debido a diferentes factores como fuente de exudados, condiciones medioambientales, clima, vegetación circundante y tiempo de recolección ${ }^{4}$. De manera general se puede indicar que el propóleo está compuesto macroscópicamente de resinas y bálsamos $(50-60 \%)$, ceras (30-40\%), aceites esenciales y aromáticos (7-10\%), polen (5\%), compuestos orgánicos (4\%), minerales (1\%), y otros como polen, mucilagos, gomas y látex.

En cuanto al contenido en materia orgánica, el propóleo contiene polifenoles, esteres, flavonoides en todas sus formas (flavonoles, flavones, flavononas, dihidroflavononas y chalconas), y ácidos fenólicos, ferúlico, cinámico y cumarina. El flavonoide crisína proporciona el color característico a propóleos y ceras. Adicionalmente se encuentran terpenos, sesquiterpenos, $\beta$-esteroides, aldehídos aromáticos y vitamina B3. La presencia en el propóleo de los diversos polifenoles le confiere propiedades farmacológicas y fisiológicas, antisépticas, antifúngicas, antibacteriales, antivirales, antioxidantes, hepatoprotectoras, cariostáticas, inmunoestimulantes y antineoplásicas ${ }^{5}$. Tanto la composición nutricional del propóleo como las propiedades anteriormente descritas lo convierten en un Alimento Funcional (AF); así al ingresar al organismo se comporta como medicamento, proporcionando un efecto benéfico para la salud ${ }^{6}$.

Actualmente el espectro de aplicación del propóleo en la industria apícola es 
129

bastante amplio y se utiliza en diferentes propósitos. Por ejemplo, en la industria farmacológica se elaboran ungüentos tópicos y ampolletas que ayudan a la buena circulación sanguínea, también en el tratamiento de forúnculos, acné, herpes simple y genital, inflamaciones orales y neurodermatitis 7; así mismo el extracto etanólico de propóleo es usado para detener el resfriado ${ }^{8}$; en la industria cosmética y de aseo personal se elaboran productos como jabón, champú, pasta dental, enjuague bucal, cremas faciales y cosméticas ${ }^{9}$.

En Suramérica, Brasil es el país líder en la producción y exportación del propóleo, y junto con Argentina tienen establecidas las normas de calidad, por ello son referentes para la valoración organoléptica, físicoquímica y nutricional del propóleo 10. Aunque Colombia, no cuenta con ningún tipo de normatividad o estándar para definir la calidad del propóleo crudo o de sus extractos, si se emplea como materia prima para elaborar productos para el cuidado de la salud y para la alimentación, lo anterior basado en los resultados de investigaciones realizadas de caracterización antimicrobiana y fisicoquímica ${ }^{11}$. El evaluar parámetros de calidad fisicoquímica, organoléptica y nutricional resulta importante para la normalización del propóleo, criterio requerido para ser usado en las industrias de alimentos y farmacéutica como también para establecer su valor comercial. Además, el propóleo crudo proveniente de diferentes regiones apícolas colombianas, se comercializa como componente activo de suplementos dietarios, tinturas y cosméticos. Valorar la actividad biológica: antimicrobiana, antioxidante y antifúngica a los propóleos colombianos, resulta también de aporte significativo para la apicultura ${ }^{10,12}$.

El objetivo de esta investigación fue caracterizar proximal y fisicoquímicamente los propóleos provenientes de apiarios de Boyacá (Colombia); de las provincias Norte (municipios de San Mateo y Boavita) y Sugamuxi (municipio de Pesca), para definir y/o valorar organoléptica y nutricionalmente cada propóleo. Además, éste conocimiento permitirá ampliar el espectro de aplicación de la industria apícola boyacense y contribuir a su valoración comercial.

\section{MATERIALES Y MÉTODOS RECOLECCIÓN DE MUESTRAS}

Las muestras de propóleo se obtuvieron a través de la Asociación de Apicultores y Criadores de Abejas 
130

de Boyacá (ASOAPIBOY), y provenían de apiarios ubicados en la provincia Norte, municipios de San Mateo y Boavita y de la provincia de Sugamuxi, municipio de Pesca. En la Tabla 1, se define la distribución geográfica y ecológica de cada municipio.

Las muestras fueron colectadas en los meses de lluvias (marzo-junio) de 2014, obtenidas de diferentes colmenas ubicadas en los respectivos apiarios, hasta formar una muestra representativa aproximada a $300 \mathrm{~g}$, utilizando el método artesanal de raspado efectuado en forma aleatoria en cada colmena. Todas las muestras fueron almacenadas en frasco ámbar a temperatura ambiente $\left(\approx 15^{\circ} \mathrm{C}\right)$ hasta su análisis el cual se llevó a cabo en el Laboratorio de Análisis de Alimentos de la Universidad Pedagógica y Tecnológica de Colombia-Tunja.

\section{DESENGRASADO}

Las muestras de propóleo de Pesca, Boavita y San Mateo, se pesaron individualmente, se fraccionaron en trozos pequeños $(\approx 2,5 \mathrm{mg})$ y se mezclaron hasta obtener un peso total de $10 \mathrm{~g}$, éste peso se utilizó para el análisis del contenido ceroso determinado por el método de extracción Soxhlet bajo las siguientes condiciones: tiempo de extracción de 6 horas a una temperatura de $60^{\circ} \mathrm{C}$ utilizando $n$-hexano como solvente. $\mathrm{E}$ porcentaje de grasa se determinó por medio de la ecuación (1).

$$
\% \text { Grasa }=\frac{M_{i}-M_{d i}}{M_{i}} * 100 \quad \text { Ec. } 1
$$

Donde $\mathrm{Mi}_{\mathrm{i}}$ equivale al peso de la muestra inicial y $M_{d}$ es el peso de la muestra desengrasada.

Posteriormente, los extractos hexanóicos de propóleo (EHP) fueron filtrados a través de papel whatman No. $1, y$ se mantuvieron en refrigeración a $4^{\circ} \mathrm{C}$ en frascos ámbar hasta su posterior análisis fisicoquímico.

\section{ANÁLISIS FISICOQUÍMICO DE LOS PROPÓLEOS BOYACENSES}

Dentro de los parámetros fisicoquímicos determinados a los extractos hexanóicos (EHP) obtenidos luego del proceso de desengrasado de los propóleos boyacenses, se encuentran el contenido de resinas, de impurezas, de acidez, densidad e índice de oxidación.

\section{Contenido de resinas}

El contenido de resinas se estableció siguiendo el método reportado por ${ }^{13}$. Se utilizaron $10 \mathrm{~g}$ de propóleo los cuales se sometieron a extracción Soxhlet con etanol (adquirido de Merck, Germany) durante $6 \mathrm{~h}$ a $80^{\circ} \mathrm{C}$, y posterior roto-evaporación durante $15 \mathrm{~min}$, a $80^{\circ} \mathrm{C}$ y 150 psi. El peso del residuo se tuvo en cuenta para 
131

determinar el porcentaje de resinas contenidas en el propóleo.

\section{Contenido de impurezas}

El remanente de las muestras obtenido de la extracción Soxhlet con etanol, se secó en estufa a $80^{\circ} \mathrm{C}$ durante $24 \mathrm{~h}, \mathrm{y}$ se llevó a un desecador por $30 \mathrm{~min}$ a temperatura ambiente, y posteriormente se pesó.

\section{Acidez}

Para la determinación de la acidez libre $(A L)$, se empleó $1 \mathrm{~mL}$ del EHP respectivo y se tituló con solución de $\mathrm{NaOH} \quad 0.1 \mathrm{~N} \quad$ (previamente estandarizada con el patrón primario, ftalato ácido de potasio); como indicador se empleó una solución alcohólica al $1 \%$ de fenolftaleína. La acidez fue reportada como porcentaje de acidez libre (\%AL).

\section{Densidad}

La densidad de los EHP a $25^{\circ} \mathrm{C}$, fue determinada usando el método de picnómetro reportado por ${ }^{14}$

\section{Índice de Oxidación (IO)}

El IO fue determinado siguiendo el método de 2 con algunas modificaciones. El EHP se diluyó con agua destilada en proporción 1:30. En un tubo de ensayo limpio y seco (pasado previamente por una mezcla sulfocrómica y lavado hasta eliminación de acidez), se colocaron $0,5 \mathrm{~mL}$ del EHP diluido, se adicionaron $0,5 \mathrm{~mL}$ de agua destilada y $1,0 \mathrm{~mL}$ de ácido sulfúrico al $20 \%$.
Todos los tubos se sometieron a refrigeración a $12^{\circ} \mathrm{C}$ usando baño de hielo. A la mezcla se le adicionaron $50 \mu \mathrm{L}$ de solución de permanganato de potasio $0,1 \mathrm{~N}$ estandarizada previamente con oxalato de sodio $0.1 \mathrm{~N}$. A continuación, se registró el tiempo de reducción (segundos) de la solución ácida de permanganato a $\mathrm{Mn}^{2+}$ detectada por la desaparición del color púrpura. El tiempo gastado para la decoloración, equivale al índice de oxidación (IO) del propóleo. El anterior tratamiento se realizó para cada una de las muestras de los propóleos boyacenses.

\section{ANÁLISIS PROXIMAL DE LOS PROPÓLEOS BOYACENSES}

Para el análisis proximal de los propóleos de San Mateo, Boavita y Pesca, se utilizó en cada caso el respectivo residuo desengrasado. La determinación del contenido de humedad se hizo a través del método de 10 ; el contenido de cenizas se determinó siguiendo el método reportado por 15; el contenido de proteína se determinó por el método micro-Kjeldahl; y el contenido de fibra usando el método AOAC 2011.25.

\section{TRATAMIENTO DE DATOS}

Todos los análisis físicos y químicos se realizaron por triplicado, y los resultados se expresaron como el promedio \pm desviación estándar.

\section{RESULTADOS Y DISCUSIÓN}


132

CARACTERÍSTICAS ORGANOLÉPTICAS, FISICOQUÍMICAS Y ANÁLISIS PROXIMAL DE LOS PROPÓLEOS BOYACENSES

Los propóleos provenientes de los apiarios de San Mateo, Pesca y Boavita-Boyacá, presentaron conglomeración en forma de briquetas debido al método de recolección (raspado) y de almacenamiento. Estructuras similares fueron referidas en el estudio realizado por ${ }^{16}$ a propóleos procedentes de la provincia de Chimborazo (Ecuador).

En cuanto a las características organolépticas, el aroma del propóleo, por lo general se debe a la riqueza en aceites esenciales, mientras que el color (de amarillo claro a castaño oscuro) y la luminosidad, corresponden a factores como el origen botánico de la resina, época de recolección y edad ${ }^{12}$. A la fecha del análisis (mes de junio/2014), el propóleo proveniente del apiario de Boavita se encontraba fresco y presentó coloración amarilla, mientras que los propóleos de San Mateo y Pesca fueron de color marrón (recolectados en el mes de marzo/2014). Adicionalmente, todas las muestras de propóleo presentaron aspecto opaco. Lo anterior posiblemente se debe a la oxidación de las resinas presentes ${ }^{17}$.

\section{Composición proximal de los propóleos}

La composición del propóleo crudo es variante y dependiente de factores, geográficos y medioambientales de la región, de la planta proveedora de resina, de la fuente de exudados, de la especie de abeja recolectora y del tiempo de recolección 10; además inciden directamente sobre la diversidad del producto y sus propiedades biológicas ${ }^{3}$. Las provincias de Boyacá: Norte (municipios de San Mateo y Boavita) y Sugamuxi (municipio de Pesca), se caracterizan por tener especies vegetales de interés apícola y medicinal 18 plantas arbóreas, arbustivas, rastreras y frutales, dando lugar a características organolépticas, fisicoquímicas y bromatológicas únicas para cada uno de los propóleos de estudio.

Los resultados de la composición proximal de los propóleos provenientes de apiarios de los tres municipios boyacenses, se muestran en la Figura 1.

A continuación, se detalla sobre cada parámetro de composición evaluado.

\section{Contenido de Humedad}

Según normas internacionales, el contenido de agua del propóleo no debe superar el $10 \%$ para evitar reacciones que generen productos indeseados $y / 0$ crecimiento de levaduras ${ }^{19}$. Sin embargo, los 
133

resultados muestran que los propóleos de Pesca y San Mateo sobrepasan el valor máximo obteniendo contenidos del $17,10 \% \pm$ 0,07 y $22,17 \% \quad \pm \quad 0,15$, respectivamente. Lo anterior, posiblemente se debe a que estos municipios están ubicados en zonas húmedas a alturas mayores a los $2000 \mathrm{msnm}$. En el caso del propóleo de Boavita su contenido de humedad fue de $5,50 \% \pm 0,14$, y cumplió con lo establecido en la norma.

\section{Contenido de Cenizas}

El contenido de cenizas encontrado en los tres propóleos fue inferior al $3 \%$ (San Mateo: 1,90\% \pm 0,14, Boavita $1,30 \% \pm 0,03$ y Pesca: $1,20 \pm$ 0,01 ), cumpliendo con lo establecido en la normatividad internacional $(<5 \%)$. Así mismo, estos resultados indican que los propóleos no han sido adulterados por los apicultores 19,20. El contenido mineral del propóleo es originado por sustancias agregadas por la abeja al momento de la recolección y brinda propiedades terapéuticas beneficiosas ${ }^{10}$. Entre los minerales presentes en el propóleo, referidos en la literatura, se destacan $\mathrm{Cu}, \mathrm{Fe}, \mathrm{Mg}$, Se, $\mathrm{Zn}, \mathrm{Si}, \mathrm{Mn}$ y $\mathrm{Mb}$ 4,12,21

\section{Contenido de Ceras}

El contenido de ceras de los propóleos de San Mateo, Pesca y Boavita, determinado mediante la extracción Soxhlet con $n$-hexano, fue similar (28-30\%), e inferior al máximo permitido por normas internacionales (35\%). No obstante, comparado con los demás nutrientes del propóleo, éste contenido resultó ser el más alto. Lo anterior, posiblemente se debe a que las abejas durante la propolinización mezclan ceras con resinas para llenar los orificios de los marcos en la colmena, y también a la presencia de compuestos bioactivos de naturaleza no polar: alcoholes y acetatos triterpénicos como $D$ y $E$ amirina y lupeol, que además ofrecen propiedades antimicrobianas ${ }^{22}$.

\section{Contenido de Resinas}

El propóleo puede clasificarse como una gomorresina con presencia de bálsamos. Por otro lado, existe una relación directa entre el contenido de resinas y la calidad del producto final del propóleo porque en esta fracción se encuentran la mayoría de compuestos que brindan actividad biológica y características particulares 23. De los tres propóleos analizados, el más resinoso fue el proveniente de Boavita $(38,03 \% \pm 0,04)$, seguido de los propóleos provenientes de Pesca $(21,35 \% \pm 0,08)$ y San Mateo $(12,75 \% \pm 0,13)$. La diferencia entre el contenido de resinas y ceras de los dos últimos propóleos, posiblemente se debe a que la vegetación circundante a los apiarios no es resinosa ${ }^{24}$; caso contrario ocurre con el propóleo del apiario de Boavita. 
134

\section{Contenido de Proteína}

El contenido de proteína del propóleo está relacionado tanto con la vegetación circundante al apiario como con el contenido de polen ${ }^{25}$. En este sentido, el propóleo proveniente del apiario de Pesca presentó el mayor contenido proteínico $(17,1 \% \pm$ $0,13)$, seguido de los propóleos de Boavita y San Mateo, cuyo contenido fue del $10,1 \% \pm 0,03$ y $7,2 \% \pm 0,06$, respectivamente. Lo anterior, muestra la variabilidad en vegetación existente en las provincias de Sugamuxi y Norte de Boyacá. El propóleo de Pesca se puede considerar como buena fuente de proteína (contenido $>10 \%$ y menor al $19 \%$, respecto a la dosis recomendada diaria, $50 \mathrm{~g}$ /2000cal/día).

\section{Contenido de Fibra}

El contenido de fibra presentó un comportamiento similar al contenido de proteína y de igual manera se relaciona con la vegetación de la zona. Al aumentar el contenido de polen o restos de plantas en el propóleo incrementa el contenido de fibra ${ }^{25}$. La concentración de fibra encontrada en los propóleos de Pesca, Boavita y San Mateo fue del $11,5 \% \pm 0,35,10,1 \% \pm 0,03$ y $7,9 \% \pm$ 0,03 , respectivamente.
Características fisicoquímicas de los propóleos boyacenses.

\section{Contenido de Impurezas}

El contenido de impurezas visibles como virutas de madera y partes de abeja fue mayor $(19,4 \% \pm 0,04)$ en el propóleo proveniente de San Mateo, comparado con Boavita y Pesca, cuyos valores fueron 3,23 y 9,7 veces más bajos. Lo anterior, se debe al método de recolección utilizado. No obstante, ningún propóleo excede el valor permitido por la Norma Argentina IRAM 15935 de 2000 (25\%) ${ }^{19,26}$.Los principales macrocomponentes, ceras, proteínas y fibra de los propóleos provenientes de los apiarios de San Mateo, Pesca y Boavita, están directamente relacionados con la acidez (Ver Figura 2). El propóleo proveniente de Pesca presentó un porcentaje de acidez libre de $53,09 \% \pm 0,03$, el de San Mateo de $46,71 \% \pm 0,06$ y el de Boavita un $46,49 \% \pm 0,04$. Esta acidez es resultado de la presencia de ácidos grasos saturados, ésteres y ácidos aromáticos, principalmente 10hidroxi-2-decenoico, benzoico, caféico y ferúlico, los cuales provienen de los exudados de las yemas vegetales (Manrique, 2000). Índice de oxidación

Este parámetro representa la cantidad de compuestos oxidantes contenidos en el propóleo. A mayor 
135

concentración de especies oxidables menor tiempo de decoloración de la solución de permanganato de potasio, y por tanto mejor calidad del producto ${ }^{27}$. Caso contrario ocurre con la concentración de especies antioxidantes. A pesar de la heterogeneidad de los propóleos de estudio, los valores registrados de $21,5 \pm 0,06,15,3 \pm 0,07$ y $6,4 \pm 0,05$ segundos, para los propóleos de San Mateo, Pesca y Boavita, respectivamente (Ver Figura 3), fueron inferiores al valor máximo establecido (22 segundos) según reglamentos internacionales $2,19,23$.

\section{Densidad}

La densidad de los propóleos boyacenses resultó ser proporcional al contenido de resinas (Ver Figura 4). El extracto hexanóico (EHP) del propóleo de Boavita fue más denso (2,68 $\pm 0,02 \mathrm{~g} / \mathrm{mL})$ comparado con los extractos de Pesca y San Mateo $(2,04 \pm 0,03$ y $1,63 \pm 0,12 \mathrm{~g} / \mathrm{mL}$, respectivamente). Caso contrario ocurrió con el índice de oxidación determinado en los EHP, puesto que fue inversamente proporcional a la cantidad de resinas presentes en los propóleos.

\section{CONCLUSIONES}

Este estudio permitió caracterizar y valorar química y fisicoquímicamente los propóleos boyacenses provenientes de las provincias de Norte (apiarios de San Mateo y Boavita) y de Sugamuxi (apiario de Pesca). Los resultados mostraron que, el propóleo proveniente de Pesca, presentó la mayor riqueza en contenido de proteína y de fibra (17,1\% y $11,5 \%$ respectivamente), y su extracto hexanóico fue más ácido (53,09\% de acidez libre), comparado con los propóleos de San Mateo y Boavita. Además, el propóleo proveniente de Boavita se caracterizó por ser el más resinoso $(38,03 \%)$; su extracto hexanóico fue el más denso $(2,64 \mathrm{~g} / \mathrm{mL})$ y además su menor índice de oxidación (6.4 s) refleja la riqueza en compuestos oxidables confiriéndole mejor calidad al producto como agente antioxidante..Comparando con lo establecido en la Norma Argentina (IRAM 15935 de 2000), el propóleo de Boavita y sus extractos hexanóicos cumplieron en mayor medida los parámetros de composición, contenidos de humedad $(5,5 \%)$, cenizas $(1,3 \%)$, ceras $(28,96 \%)$, resinas $(35,5 \%)$ e índice de oxidación (6,45 segundos).

\section{Referencias bibliográficas}

1.-Haile, K., Kebede, T., \& Dekebo, A. (2012). A comparative study of volatile components of propolis (bee glue) collected from Haramaya University and 
Assela beekeeping centers, Ethiopia. Bulletin of the Chemical Society of Ethiopia, 26(3), 353-360. doi: 10.4314/bcse.v26i3.4

free radical-induced erythrocyte damage and inhibition of human renal cancer cell growth in vitro. Food Chem Toxicol, 49(1), 8692. doi:

2.-Salamanca Grosso, G., Correa 10.1016/j.fct.2010.10.001

Carvajal, I. L., \& Principal, J. (2007). Perfil de flavonoides e índices de oxidación de algunos propóleos colombianos. Zootecnia Tropical, 25(2), 95-102.

3.-Alves Ferreira, E. M., Guzmán, D., Figueroa, J., Tello, J., \& Scoaris, D. D. O. (2011). Caracterización antimicrobiana y fisicoquímica de propóleos de Apis mellifera $L$. (Hymenoptera: Apidae) de la región andina colombiana. Acta Biológica Colombiana, 16(1), 175-184.

4.-Valencia, D., Alday, E., RoblesZepeda, R., Garibay-Escobar, A., Galvez-Ruiz, J. C., SalasReyes, M.,Velazquez, C. (2012). Seasonal effect on chemical composition and biological activities of Sonoran propolis. Food Chemistry, 131(2), 645-651. doi: 10.1016/j.foodchem.2011.08.0 86

5.-Valente, M. J., Baltazar, A. F., Henrique, R., Estevinho, L., \& Carvalho, M. (2011). Biological activities of Portuguese propolis: protection against

6.-Cortés Díaz, G. M., Prieto Suárez, G. A., \& Rozo Nuñez, W. E. (2015). Caracterización bromatológica y fisicoquímica de la uchuva (Physalis peruviana L.) y su posible aplicación como alimento nutracéutico. Ciencia en Desarrollo [online]. 6(1), 87-97.

7.-Abozid, M., \& El-Kaway, A. (2013). Chemical composition of Egyptian and commercial propolis and its effects on liver function and lipid profiles in albino rats. J. of Biological Chem. Env. Res., 8(2), 323340.

8.-Palomino García, L. R., Martínez Galán, J. P., García Pajón, C. M., Gil González, J. H., \& Durango Restrepo, D. L. (2010). Caracterización Fisicoquímica y Actividad Antimicrobiana del Propóleos en el Municipio de La Unión (Antioquia, Colombia). Revista Facultad Nacional de Agronomía, 63(1), 5373-5383.

9.-Santos, F. A., Bastos, E. M., Maia, A. B., Uzeda, M., Carvalho, M. A., Farias, L. M., \& Moreira, E. S. (2003). Brazilian propolis: 
physicochemical properties, plant origin and antibacterial activity on periodontopathogens.

Phytother Res, 17(3), 285-289. doi: 10.1002/ptr.1117

10.-Viloria B., J. D., Gil G., J. H., Durango R., D. L., \& García P., C. M. (2012). Caracterización fisicoquímica del propóleo de la región del bajo Cauca Antioqueño (Antioquia, Colombia). Biotecnología en el Sector Agropecuario y Agroindustrial, 10(1), 77-86.

11.-Hernández, D., Figueroa, J., \& Talero, C. (2012). Calidad microbiológica de propóleo crudo y sólidos solubles de extractos de propóleos de Apis mellifera en Colombia. Revista de la Facultad de Medicina Veterinaria y de Zootecnia, 59(II), 109-118.

12.-Vargas-Sánchez, R. D., Torrescano-Urrutia, G. R., \& Sánchez-Escalante, A. (2013). El propóleos: conservador potencial para la industria alimentaria. Interciencia, 38(10), 705-711.

13.-Negri, G., Marcucci, M., Cristina, Salatino, A., \& Salatino, M. L., Faria. (1998). Hydrocarbons and monoesters of propolis waxes from Brazil. Apidologie, 29(4), 305-314.
14.-Mello, B. C. B. S., Petrus, J. C. C., \& Dupas, M. (2013). Nanofiltration of Aqueous Propolis Extracts and the Effects of Temperature, Pressure and $\mathrm{pH}$ in the concentrated Product Studies in Chemical Process Technology (SCPT), 1(4), 5565.

15.-Lozina, L., Peichoto, M., Acosta, O., \& Granero, G. (2010). Estandarización Caracterización Organoléptica y Físico-Química de 15 Propóleos Argentinos. Latin American Journal of Pharmacy, 29(1), 102-110

16.-Angulo, J. (2014). Caracterización $y$ actividad antioxidante de propóleos de diferentes zonas apícolas de la provincia de chimborazo utilizados en la empresa Apicare - Riobamba. (Bioquímico Farmacéutico), Escuela Superior Politécnica del Chimborazo, Riobamba.

17.-Gonzalez, J., Sosa López, A., Maidana, J., Subovski, M., \& Castillo, A. (2003). Determinación de ciertos parámetros para caracterizar propóleos argentinos. 1-4. Retrieved from Apicultura website:

http://www.apiservices.com/arti culos/propoleos_argentinos.ht $\mathrm{m}$

18.-Barrios-Paternina, E., \& MercadoGómez, J. (2014). Plantas 
útiles del corregimiento Santa Inés y la vereda San Felipe (San Marcos, Sucre, Colombia). Ciencia en Desarrollo, 5, 131-144.

19.-Norma-IRAM. (2000). Normas IRAM-INTA 15935: Propóleos $y$ sus extractos. Argentina: Instituto Argentino De Normalización Retrieved from file:///F:/ARTICULOS/PROPOL EO/Norma\%201ram\%20propol eo.htm.

20.-Cunha, I. B. S., Sawaya, A. C. H. F., Caetano, F. M., Shimizu, M. T., Marcucci, M. C., Drezza, F. T., . . . Carvalho, P. d. O. (2004). Factors that influence the yield and composition of Brazilian propolis extracts. Journal of the Brazilian Chemical Society, 15(6), 964970. doi: 10.1590/S010350532004000600026

21.-Viuda-Martos, M., Ruiz-Navajas, Y., Fernandez-Lopez, J., \& Perez-Alvarez, J. A. (2008). Functional properties of honey, propolis, and royal jelly. J Food Sci, 73(9), R117-124. doi: $10.1111 / \mathrm{j} .1750-$

3841.2008.00966.x

22.-Custodio, A. R., Ferreira, M. M. C., Negri, G., \& Salatino, A. (2003). Clustering of comb and propolis waxes based on the distribution of aliphatic constituents. Journal of the Brazilian Chemical Society, 14(3), 354-357. doi: $10.1590 / \mathrm{S} 0103-$ 50532003000300003

23.-Lacalle, A. (2008). Propoleo, el" antibiótico" natural de la colmena. Sustrai: revista agropesquera(85), 56-61.

24.-Chaillou, L. L., Herrera, H. A., \& Maidana, J. F. (2004). Estudio del propoleos de Santiago del Estero, Argentina. Food Science and Technology (Campinas), 24(1), 11-15. doi: $10.1590 / \mathrm{S} 0101$ 20612004000100003

25.-Yoong, A. (2004). Caracterización físico-química del propóleo de la Escuela Agrícola Panamericana y su efecto antioxidante en aceite de soya. (Ingeniera Agroindustrial), Zamorano, Honduras.

26.-Alvarez, S. (2012). Caracterización organoléptica y físico-química de propóleos del departamento de La Libertad, Perú. Biologist, 10(1), 34-40.

27.-Martínez G, J., García $P, C$., Durango R, D., \& Gil G, J. (2012). Caracterización de propóleos provenientes del municipio de Caldas obtenido por dos métodos de recolección. Revista MVZ Cordoba, 17(1), 2861-2869. 
Tabla 1. Distribución geográfica y ecológica de municipios boyacenses

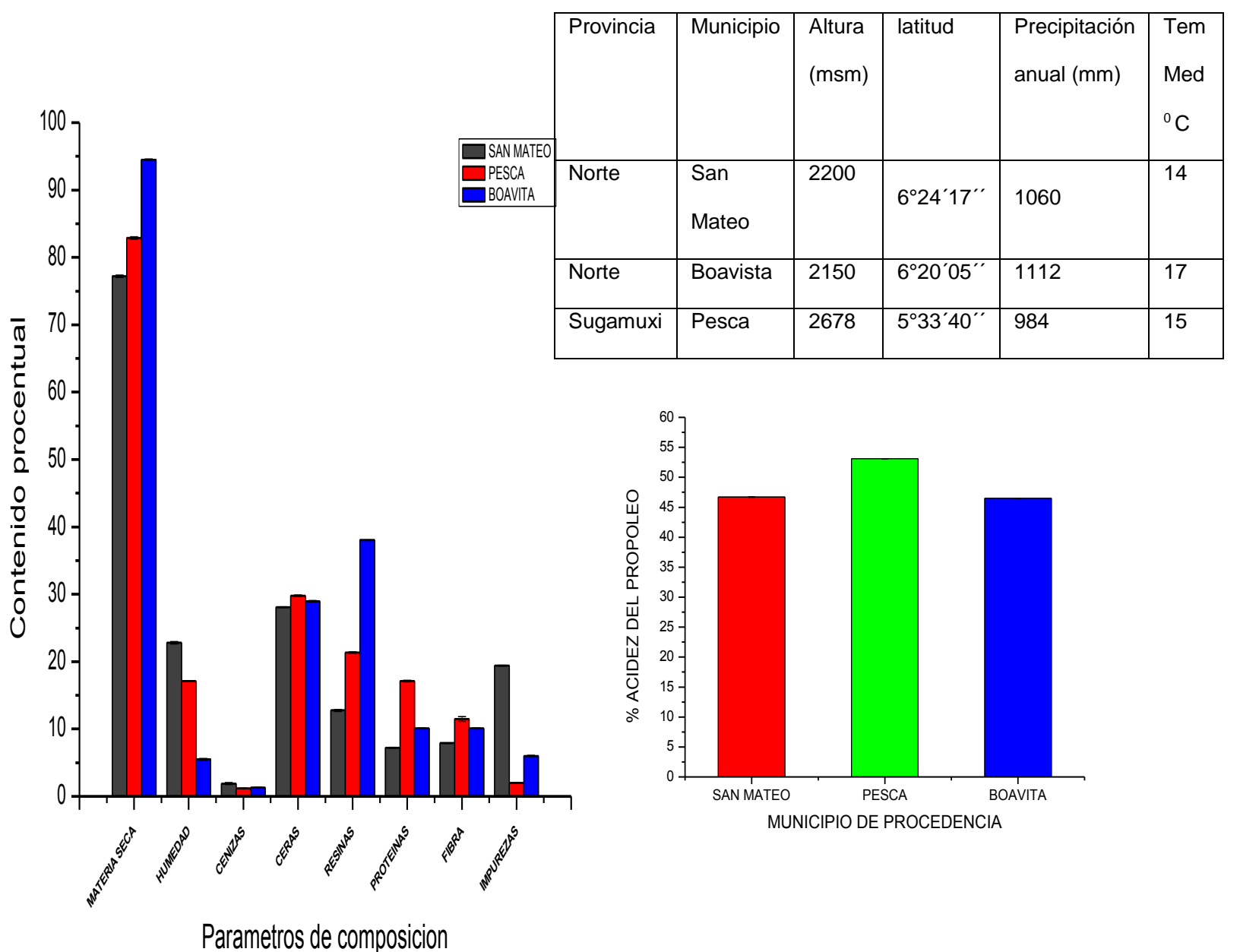

Figura 1. Análisis proximal y fisicoquímico de propóleos

Figura 1. Índice de oxidación de propóleos provenientes de apiarios boyacenses. boyacenses

Figura 2. Porcentaje de acidez libre de propóleos boyacenses 


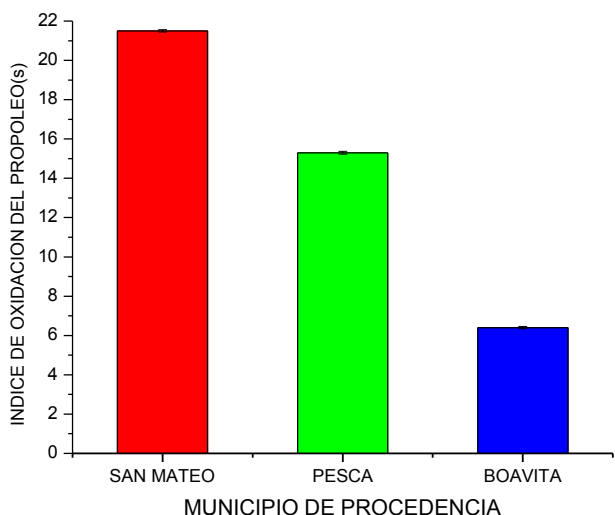

Figura 4 Densidad de propóleos boyacenses

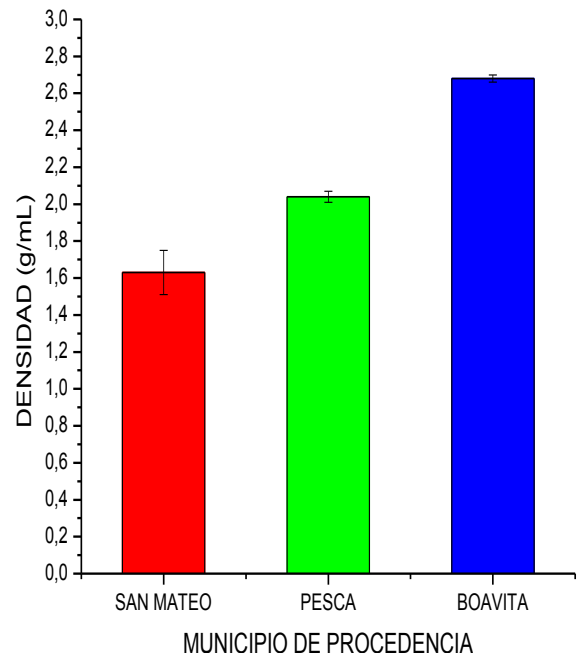

